\title{
Elas na Computação: Decifrando Códigos e Expressando Ideias Críticas e Criativas na Escola
}

\author{
Keila Paula de Alcântara \\ Departamento de Computação \\ UFRPE / Recife-PE / Brasil \\ keilalcantara.ac@gmail.com
}

\author{
Laura Gabrielle de Lira Silva \\ Departamento de Computação \\ UFRPE / Recife-PE / Brasil \\ lauragabrielle46@gmail.com
}

\author{
Maiara Santos de Souza \\ Departamento de Computação \\ UFRPE / Recife-PE / Brasil \\ maiarasouzaz.lc@gmail.com
}

\author{
José Alexandre da Silva \\ ETEPD \\ SEE/ Recife-PE / Brasil \\ jas@etepd.com.br
}

\author{
Rozelma Soares de França \\ Departamento de Educação \\ UFRPE / Recife - PE / Brasil \\ rozelma.franca@ufrpe.br
}

O ingresso de mulheres na computação é uma problemática que enfrentamos há muito tempo. Segundo dados do Inep de 2018 [1], o percentual de mulheres matriculadas no curso de Ciência da Computação passou de 34,8\% para 15,5\% no Brasil. Um recente relatório da UNESCO [2] revela que as diferenças de gênero na participação na educação em STEM em detrimento das meninas já são visíveis na educação infantil, e se tornam ainda mais visíveis nos níveis de ensino mais altos. Tal documento ainda reforça que os sistemas educacionais desempenham um papel central em determinar o interesse das meninas e oferecer oportunidades iguais para acessarem e se beneficiarem de uma educação em STEM de qualidade.

A partir disso, surge o seguinte questionamento: "Como despertar o interesse de meninas pela área de computação?". Com base em pesquisas, identificamos estudos na área que demonstram resultados satisfatórios a partir de ações realizadas na educação básica [3. 4]. É neste contexto que surge esta proposta, a partir da atuação do PIBID Computação UFRPE na ETEPD, a fim de contribuir para uma educação em computação mais equânime e de qualidade.

Para entender efetivamente as dificuldades e necessidades da escola, uma pesquisa etnográfica [5] foi realizada de forma virtual, devido à pandemia de COVID-19, se apoiando em diferentes instrumentos de coleta de dados: busca de informações sobre a escola na rede, acompanhamento de aulas, construção e aplicação de questionários com a comunidade escolar - professores e estudantes; e entrevistas com as OxenteGirls (grupo formado por estudantes da escola para incentivar meninas na área de computação). A partir da análise desses dados, este projeto foi idealizado.

\footnotetext{
Fica permitido ao(s) autor(es) ou a terceiros a reprodução ou distribuição, em parte ou no todo, do material extraído dessa obra, de forma verbatim, adaptada ou remixada, bem como a criação ou produção a partir do conteúdo dessa obra, para fins não comerciais, desde que sejam atribuídos os devidos créditos à criação original, sob os termos da licença CC BY-NC 4.0.

EduComp'21, Abril 26-30, 2021, Jataí, Goiás, Brasil (On-line)

(C)2021 Copyright mantido pelo(s) autor(es). Direitos de publicação licenciados à Sociedade Brasileira de Computação (SBC).
}

A partir dos dados coletados [6] foi possível perceber que a escola oferece às estudantes um aparato importante que tenta oferecer uma equidade de gênero. Contudo, os dados também revelam uma baixa identificação das estudantes participantes com o curso técnico e que elas sofrem com o machismo vindo dos colegas. A partir dessas inquietações, um conjunto de ações foi planejado visando apoiá-las durante suas formações na área tecnológica [7]. Tais ações perpassam: i) realização de oficinas com atividades que estimulem o pensamento computacional de forma criativa; ii) análise de aplicações, tais como o Google Tradutor, e seus algoritmos sexistas associados, de forma crítica e conduzindo à proposição de soluções aos problemas identificados; iii) rodas de diálogo e criação de materiais didáticos com e sobre mulheres que foram e são referências na área de computação; e iv) discussões sobre machismo em games (jogos online e mercado de trabalho) com a participação também dos meninos, visando sua reflexão e mudança de comportamentos machistas.

\section{AGRADECIMENTOS}

O presente trabalho foi realizado com apoio do Programa Institucional de Bolsa de Iniciação à Docência (PIBID) da Coordenação de Aperfeiçoamento de Pessoal de Nível Superior (CAPES) - Edital 02/2020.

\section{REFERÊNCIAS}

[1] ANDRADE, Rodrigo de Oliveira. A retomada do espaço da mulher na computação, 2019. Disponível em < https://revistapesquisa.fapesp.br/aretomada-do-espaco-da-mulher-na-computacao/\#: :text $=0 \% 20 \mathrm{n}>$

[2] UNESCO. Decifrar o código: educação de meninas e mulheres em ciências, tecnologia, engenharia e matemática (STEM), 2018. Disponível em < https://unesdoc.unesco.org/ark:/48223/pf0000264691>. Acesso em 15 de fev. 2021.

[3] MARQUIORI, Vânia Silvares. e OLIVEIRA, Márcia Gonçalves de. O Pensamento Computacional na Compreensão de Problemas do Cotidiano Feminino para o Letramento em Programação, 2019. Disponível em <https://www.br-ie.org/pub/index.php/wcbie/article/view/8992/6541>. Acesso em 10 de jan. de 2021.

[4] PINTO, N et al. Quando a Aluna se Torna a Mestre: Um Relato da Experiência de Alunas de Graduação Aplicando Dinâmicas de Ensino de Computação para Alunas de Ensino Médio, 2020. Disponível em 
<https://sol.sbc.org.br/index.php/wei/article/view/11125/10996>.

Acesso em 10 de jan. de 2021.

[5] CRESWELL, John W. Investigação Qualitativa e Projeto de Pesquisa: Escolhendo entre Cinco Abordagens. 3 ed. Porto Alegre: Penso, 2014.

[6] Universidade Federal Rural de Pernambuco (2021). Diagnose PIBID/UFRPE - Edital Capes 02/2020 Licenciatura em Computação - Escola Técnica Estadual Porto Digital. Disponível em $<$ https://www.flipsnack.com/pibidlions/portf-lio-pibid-computa-o-eteporto-digital.html>. Acesso em 20 de jan. 2021. 